\title{
Psychiatric Hospital staff's depression indices were not influenced by deinstitutionalization but by gender and years in work Georgios Giaglis*1,2, Konstantina Mantziava ${ }^{2}$ and Georgios Angelidis ${ }^{1}$
}

\author{
Address: ${ }^{1}$ Psychiatric Hospital of Petra Olympus, Katerini, Greece and ${ }^{2}$ Psychology Department, Aristotle University of Thessaloniki, Greece \\ * Corresponding author
}

from International Society on Brain and Behaviour: 3rd International Congress on Brain and Behaviour

Thessaloniki, Greece. 28 November - 2 December 2007

Published: 17 April 2008

Annals of General Psychiatry 2008, 7(Suppl I):S346 doi:I0.1 186/I744-859X-7-SI-S346

This abstract is available from: http://www.annals-general-psychiatry.com/content/7/SI/S346

(c) 2008 Giaglis et al.; licensee BioMed Central Ltd.

\section{Background}

The aim of this study was to assess the staff's depression levels of a Psychiatric Hospital that has undergone transformation to a network of community-based psychiatric facilities.

\section{Materials and methods}

The Greek adaptation of Zung Depression self-Rating Scale (ZDRS) was anonymously completed by the working staff two years before and two years after the transformation of their hospital.

\section{Results}

Internal consistency of the scale was satisfactorily high in both administrations of the scale [Cronbach's a>0.80]. Deinstitutionalization had no statistically significant impact either on the overall depression scores as measured by the Symptoms Severity Score (SDS). There was no significant difference on the number of staff that had clinical (SDS>70), mild (SDS:60-69) or minimal $/ \mathrm{mild}$ (SDS:50-59) depression levels $[\mathrm{x} 2(3)=1.07, \mathrm{p}=\mathrm{NS}]$ or were overall classified as depressed $[\mathrm{x} 2(1)=0.568, \mathrm{p}=\mathrm{NS}]$. Regarding specific items, after the deinstitutionalization people reported enjoying sex less, but regarding their lives as being more full. On the other hand, there was a mild correlation between SDS and years of work $[\mathrm{r}=0.137$, $\mathrm{p}<0.05]$, as well as a significant effect of the female gender, after correction for age and years of work $[F(1,242)=13.19, \mathrm{p}<0.001]$. Women scored worse on items regarding affection and somatic concerns.

\section{Conclusions}

This follow-up study verifies the previously found effects of the staff's gender and years of previous service on depression as measured by the ZDRS. The transformation of their hospital into community-based psychiatric facilities, as a direct result of the deinstitutionalization project, did not affect the staff's depression levels. 